Virginia Commonwealth University

vCU Scholars Compass

2014

\title{
Proton-bound dimers of nitrogen heterocyclic molecules: Substituent effects on the structures and binding energies of homodimers of diazine, triazine, and fluoropyridine
}

Isaac K. Attah

Virginia Commonwealth University, attahi@vcu.edu

Sean P. Platt

Virginia Commonwealth University, plattsp@vcu.edu

Michael Mautner

Virginia Commonwealth University, mmautner@vcu.edu

See next page for additional authors

Follow this and additional works at: http://scholarscompass.vcu.edu/chem_pubs

Part of the Chemistry Commons

Attah, I. K., Platt, S. P., \& Mautner, M., et al. Proton-bound dimers of nitrogen heterocyclic molecules: Substituent effects on the structures and binding energies of homodimers of diazine, triazine, and fluoropyridine. The Journal of Chemical Physics, 140, 114313 (2014). Copyright (C) 2014 AIP Publishing LLC.

\section{Downloaded from}

http://scholarscompass.vcu.edu/chem_pubs/65

This Article is brought to you for free and open access by the Dept. of Chemistry at VCU Scholars Compass. It has been accepted for inclusion in Chemistry Publications by an authorized administrator of VCU Scholars Compass. For more information, please contact libcompass@vcu.edu. 
Authors

Isaac K. Attah, Sean P. Platt, Michael Mautner, M. S. El-Shall, Saadullah G. Aziz, and Abdulrahman O. Alyoubi 


\title{
Proton-bound dimers of nitrogen heterocyclic molecules: Substituent effects on the structures and binding energies of homodimers of diazine, triazine, and fluoropyridine
}

\author{
Isaac K. Attah, ${ }^{1}$ Sean P. Platt, ${ }^{1}$ Michael Meot-Ner (Mautner), ${ }^{1}$ M. S. El-Shall, ${ }^{1, a)}$ \\ Saadullah G. Aziz, ${ }^{2}$ and Abdulrahman O. Alyoubi ${ }^{2}$ \\ ${ }^{1}$ Department of Chemistry, Virginia Commonwealth University, Richmond, Virginia 23284-2006, USA \\ ${ }^{2}$ Department of Chemistry, Faculty of Science, King Abdulaziz University, Jeddah 21589, Saudi Arabia
}

(Received 3 January 2014; accepted 19 February 2014; published online 21 March 2014)

\begin{abstract}
The bonding energies of proton-bound homodimers $\mathrm{BH}^{+} \mathrm{B}$ were measured by ion mobility equilibrium studies and calculated at the DFT B3LYP/6-311++ $\mathrm{G}^{* *}$ level, for a series of nitrogen heterocyclic molecules (B) with electron-withdrawing in-ring $\mathrm{N}$ and on-ring $\mathrm{F}$ substituents. The binding energies $\left(\Delta \mathrm{H}^{\circ}{ }_{\text {dissoc }}\right)$ of the proton-bound dimers $\left(\mathrm{BH}^{+} \mathrm{B}\right)$ vary significantly, from 29.7 to $18.1 \mathrm{kcal} / \mathrm{mol}$, decreasing linearly with decreasing the proton affinity of the monomer (B). This trend differs significantly from the constant binding energies of most homodimers of other organic nitrogen and oxygen bases. The experimentally measured $\Delta \mathrm{H}^{\circ}{ }_{\text {dissoc }}$ for (1,3-diazine $)_{2} \mathrm{H}^{+}$, i.e., (pyrimidine) ${ }_{2} \mathrm{H}^{+}$and (3-F-pyridine) ${ }_{2} \mathrm{H}^{+}$are 22.7 and $23.0 \mathrm{kcal} / \mathrm{mol}$, respectively. The measured $\Delta \mathrm{H}^{\circ}{ }_{\text {dissoc }}$ for the pyrimidine $\cdot+(3$-F-pyridine $)$ radical cation dimer $(19.2 \mathrm{kcal} / \mathrm{mol})$ is signifcantly lower than that of the proton-bound homodimers of pyrimidine and 3-F-pyridine, reflecting the stronger interaction in the ionic $\mathrm{H}$-bond of the protonated dimers. The calculated binding energies for (1,2-diazine $)_{2} \mathrm{H}^{+}$, (pyridine $)_{2} \mathrm{H}^{+},(2 \text {-F-pyridine })_{2} \mathrm{H}^{+},(3 \text {-F-pyridine })_{2} \mathrm{H}^{+},(2,6$-diF-pyridine $)_{2} \mathrm{H}^{+}$, (4-F-pyridine $)_{2} \mathrm{H}^{+},(1,3 \text {-diazine })_{2} \mathrm{H}^{+}$, (1,4-diazine $)_{2} \mathrm{H}^{+},\left(1,3,5\right.$-triazine ${ }_{2} \mathrm{H}^{+}$, and (pentafluoropyridine) ${ }_{2} \mathrm{H}^{+}$are $29.7,24.9,24.8,23.3,23.2,23.0,22.4,21.9,19.3$, and $18.1 \mathrm{kcal} / \mathrm{mol}$, respectively. The electron-withdrawing substituents form internal dipoles whose electrostatic interactions contribute to both the decreased proton affinities of (B) and the decreased binding energies of the protonated dimers $\mathrm{BH}^{+} \mathrm{B}$. The bonding energies also vary with rotation about the hydrogen bond, and they decrease in rotamers where the internal dipoles of the components are aligned efficiently for inter-ring repulsion. For compounds substituted at the 3 or 4 (meta or para) positions, the lowest energy rotamers are T-shaped with the planes of the two rings rotated by $90^{\circ}$ about the hydrogen bond, while the planar rotamers are weakened by repulsion between the ortho hydrogen atoms of the two rings. Conversely, in ortho-substituted (1,2-diazine) ${ }_{2} \mathrm{H}^{+}$and (2-F-pyridine) ${ }_{2} \mathrm{H}^{+}$, attractive interactions between the ortho $(\mathrm{C}-\mathrm{H})$ hydrogen atoms of one ring and the electronegative ortho atoms ( $\mathrm{N}$ or $\mathrm{F})$ of the other ring are stabilizing, and increase the protonated dimer binding energies by up to $4 \mathrm{kcal} / \mathrm{mol}$. In all of the dimers, rotation about the hydrogen bond can involve a 2-4 kcal $/ \mathrm{mol}$ barrier due to the relative energies of the rotamers. () 2014 AIP Publishing LLC. [http://dx.doi.org/10.1063/1.4867288]
\end{abstract}

\section{INTRODUCTION}

Aromatic nitrogen heterocyclic compounds occur in environments ranging from biochemistry and pharmacology to synthetic chemistry, environmental chemistry, meteorites, interstellar clouds, astrochemistry, and astrobiology. ${ }^{1-5}$ These nitrogen bases can be protonated in solution by acids, and in the gas phase through ions produced by radiation. The protonated bases can then form strong ionic hydrogen bonds with neutral solvent molecules or bases, including neutral nitrogen heterocyclics. ${ }^{4,5}$ These hydrogen bonds contribute to ion solvation, and biological and crystal structures. Complexes with strong ionic hydrogen bonds were reviewed recently. ${ }^{6}$

An important class of ionic hydrogen bonded systems is the proton-bound dimers where a bridging proton connects two electronegative centers in two molecules. ${ }^{7-26}$ The

\footnotetext{
a) Author to whom correspondence should be addressed. Electronic mail: mselshal@vcu.edu
}

thermochemistry of hydrogen bonded heterodimers $\mathrm{AH}^{+} \cdot \mathrm{B}$ (where $\mathrm{B}=\mathrm{H}_{2} \mathrm{O}$ ) of nitrogen heterocyclics was studied in pyridine derivatives with electron donating or withdrawing substituents, and several structural features have been identified including steric effects in hindered alkylpyridines and multiple hydrogen bonds in protonated dimers of nucleic bases. ${ }^{7,9,12}$ A general feature of these $\mathrm{AH}^{+} \cdot \mathrm{B}$ dimers (Eq. (1)) is an inverse relation between the differences of the proton affinities of $\mathrm{A}$ and $\mathrm{B}$ molecules (i.e., $\triangle \mathrm{PA}$ $=\mathrm{PA}(\mathrm{A})-\mathrm{PA}(\mathrm{B}))$ and the ionic hydrogen bond strength (i.e., $\left.-\Delta \mathrm{H}^{\circ} \mathrm{D}\left(\mathrm{AH}^{+} \cdot \mathrm{B}\right)\right)$ as shown by Eq. (2). This inverse relationship has been observed for protonated dimers of various nitrogen, oxygen, and sulfur bases over PA differences as large as $60 \mathrm{kcal} / \mathrm{mol}::^{7,11,13}$

$$
\begin{gathered}
\mathrm{AH}^{+}+\mathrm{B} \rightarrow \mathrm{AH}^{+} \cdot \mathrm{B}, \\
-\Delta \mathrm{H}_{\mathrm{D}}^{\circ}\left(\mathrm{AH}^{+} \cdot \mathrm{B}\right)=\mathrm{a}-\mathrm{b} \Delta \mathrm{PA},
\end{gathered}
$$


where $\mathrm{a}$ and $\mathrm{b}$ are parameters obtained from the linear fitting of $-\Delta \mathrm{H}^{\circ}{ }_{\mathrm{D}}\left(\mathrm{AH}^{+} \cdot \mathrm{B}\right)$ and $\triangle \mathrm{PA}$. For nitrogen bases such as amines and pyridines, a is usually $24 \pm 1 \mathrm{kcal} / \mathrm{mol}$ and $\mathrm{b}$ is about 0.3 . Therefore, for homodimers, where $\Delta \mathrm{PA}=0$, this empirical relation predicts $\Delta \mathrm{H}^{\circ}{ }_{\mathrm{D}}\left(\mathrm{BH}^{+} \cdot \mathrm{B}\right)=24 \pm 1 \mathrm{kcal} / \mathrm{mol}$ for all of these bases regardless of the absolute proton affinities of the bases.

In such homodimers $\mathrm{B}_{2} \mathrm{H}^{+}$(i.e., $\mathrm{BH}^{+} \cdot \mathrm{B}$ ), the proton is shared efficiently between the two components which of course have equal proton affinities. As PA(B) increases, the protonated component $\left(\mathrm{BH}^{+}\right)$becomes a less efficient proton donor, weakening the hydrogen bond $\left(\mathrm{BH}^{+} \ldots \mathrm{B}\right)$, while the neutral component (B) becomes a more efficient proton acceptor because of the increased PA, thus strengthening the bond. ${ }^{1,7,11,14}$ These effects can cancel and the dissociation energies $\Delta \mathrm{H}^{\circ}{ }_{\mathrm{D}}\left(\mathrm{B}_{2} \mathrm{H}^{+}\right)$remain nearly constant for homodimers $\mathrm{B}_{2} \mathrm{H}^{+}$regardless of the proton affinity of the monomer, $\mathrm{PA}(\mathrm{B})$. For alkylamine and alkylpyridine bases $\Delta \mathrm{H}^{\circ}{ }_{\mathrm{D}}\left(\mathrm{B}_{2} \mathrm{H}^{+}\right)$ is nearly constant at $24 \pm 2 \mathrm{kcal} / \mathrm{mol}$ for compounds with proton affinities ranging over $30 \mathrm{kcal} / \mathrm{mol}$. For example, for both $\left(\mathrm{NH}_{3}\right)_{2} \mathrm{H}^{+}$and (pyridine) $)_{2} \mathrm{H}^{+}$the binding energy is 24 $\pm 2 \mathrm{kcal} / \mathrm{mol}$ although $\mathrm{PA}(\mathrm{B})$ changes from $\mathrm{PA}\left(\mathrm{NH}_{3}\right)=204$ $\mathrm{kcal} / \mathrm{mol}$ to $\mathrm{PA}($ pyridine $)=222 \mathrm{kcal} / \mathrm{mol}$, and the structures of the bases are also very different. ${ }^{1,27}$ Similarly, for oxygen bases with different PAs over a range of $40 \mathrm{kcal} / \mathrm{mol}$, bond energies of the protonated homodimers are nearly constant between 30 and $32 \mathrm{kcal} / \mathrm{mol}^{12,14,28}$

However, the bonding energies can be affected by structural effects. For example, multiple hydrogen bonds in the protonated dimers of nucleic bases increase the dimer bonding energies by up to $6 \mathrm{kcal} / \mathrm{mol}$ per extra bond. ${ }^{9,15}$ Another structural effect was observed in dimer ions of 2,6alkylpyridines with bulky alkyl substituents. The hydrogen bonds were not strained even with bulky ortho substituents, but steric hindrance to rotation about the hydrogen bond leads to large negative entropy change upon dimer formation. ${ }^{12,29}$

In the present work, we examine protonated homodimers of aromatic nitrogen heterocyclics, i.e., diazines (1,2diazine, 1,3-diazine, and 1,4-diazine), 1,3,5-triazine, and also some fluoropyridines (2-F-pyridine, 3-F-pyridine, 4F-pyridine, 2,6-difluoro-pyridine, and pentafluoro-pyridine). The electron withdrawing substitution in the six-membered pyridine ring decreases the proton affinities over a range of almost $40 \mathrm{kcal} / \mathrm{mol}$ from $222.0 \mathrm{kcal} / \mathrm{mol}$ for pyridine to $202.9 \mathrm{kcal} / \mathrm{mol}$ for $1,3,5$-triazine and $182.8 \mathrm{kcal} / \mathrm{mol}$ for pentafluoropyridine. These changes in proton affinity may be due to effects other than changes in polarizability with alkylation. For example, electron withdrawing substituents may form intramolecular dipoles that are repulsive to an added proton, thus lowering the proton affinity of base (B). The electron withdrawing substituents may also place less electron density in the vicinity of the bridging proton leading to a weaker bond. These related effects on the proton affinities and dimer binding energies can lead to a correlation of decreasing proton affinities and hydrogen bond energies. In these cases, the increased proton donor strength of the protonated component does not fully compensate for the decreased proton acceptor strength of the neutral base caused by the electronegative substituents. Here, we shall examine these effects in protonated homodimers of the azines and flurobenzenes with electronwithdrawing substituents.

\section{EXPERIMENTAL SECTION}

The equilibrium thermochemical measurements reported here were carried out using the Virginia Commonwealth University (VCU) mass-selected ion mobility mass spectrometer. Details of the instrument were given in Refs. 30-34. The pyrimidine (1,3-diazine) and 3-F-pyridine radical cations were generated by $70 \mathrm{eV}$ electron impact ionization of the neutral monomers that were introduced to the ion source by supersonic expansion of 40 psi (2.8 bars) of ultra-pure helium seeded with about $1 \%-4 \%$ of vapor of the corresponding compound (pyrimidine and 3-fluoropyridine, respectively) through a pulsed supersonic nozzle $(500 \mu \mathrm{m})$ to the vacuum source chamber with $10^{-7}$ Torr pressure. The radical cations were then mass selected using a first quadrupole mass-filter, and injected in 30-50 $\mu$ s pulses into the drift cell. The ions are injected into the mobility cell with injection energies of 8-14 eV, laboratory frame, just above the minimum energies required to introduce the ions into the cell against the backward flow of the gas mixture from the drift cell entrance orifice. Most of the thermalization of the injected ion occurs just outside the cell entrance by collisions with the monomer molecules and He atoms escaping from the cell. ${ }^{30-32}$ Further thermalization occurs in the mobility cell. For example, at a cell pressure of 0.2 Torr, the number of collisions of an ion with the neutral molecules within the $1.5 \mathrm{~ms}$ residence time inside the cell is about $10^{4}$ collisions. ${ }^{30-32}$ The number of collisions necessary for thermalization (about 100) can therefore occur within the first $1 \%$ of the ion drift time or distance.

The reaction mixture in the cell contained a neutral monomer/helium buffer gas mixture. A constant concentration of the neutral monomer in the drift cell was maintained using flow controllers (MKS \#1479A), which are accurate to within \pm 1 mTorr. The drift cell temperature was controlled within $\pm 1 \mathrm{~K}$ using four temperature controllers. The injected radical ions react with the neutral molecules in the drift cell through self-protonation forming the protonated monomer, followed by association to form the protonated dimer. An alternative method to generate the protonated monomer was used by injecting methanol radical cations generated in the ion source into the drift cell containing a 3-F-pyridine/helium mixture. The protonated dimer [(3-F-pyridine $\left.)_{2} \mathrm{H}^{+}\right]$was formed through a series of reactions that generate $(3-\mathrm{F}$-pyridine $) \mathrm{H}^{+}$followed by the addition of the neutral 3-F-pyridine monomer.

The reactant and product ions exiting the drift cell were scanned and detected using second quadrupole mass filter and detector assembly. The arrival time distributions (ATDs) were collected by monitoring the intensity of each ion as a function of the drift time, by varying the drift cell voltage that changes the drift time, i.e., reaction time.

\section{COMPUTATIONAL SECTION}

Density Functional Theory (DFT) computations of the lowest energy geometries for the various protonated dimers were performed at the B3LYP/6-311++ $\mathrm{G}^{* *}$ level of theory 
using the Gaussian 03 program suite. ${ }^{35}$ Vibrational frequency calculations were also performed for all the optimized geometries at the same level of theory in order to obtain zero point vibrational energy (ZPVE) and also to verify the absence of any imaginary frequencies. ${ }^{35}$ Frequency calculations to measure rotational barriers were performed on non-optimized geometries, which were derived by rotating one cyclic ring in the optimized structure along the $\mathrm{N}-\mathrm{H}$ axis. The absence of a true ground state as a transition structure for rotation about the hydrogen bond was verified by the presence of one or more imaginary frequencies. Attempts to optimize these modified structures produced the original ground state geometry. Charge densities were obtained by population analysis using the natural bond orbital method at the B3LYP/6-311++ $\mathrm{G}^{* *}$ level of theory after the frequency calculations. Corrections to basis set superposition error (BSSE) were made only for the (pyrimidine) ${ }_{2} \mathrm{H}^{+}$and (3-F-pyridine) ${ }_{2} \mathrm{H}^{+}$dimers since these corrections were found to be small $(0.4-0.8 \mathrm{kcal} / \mathrm{mol})$.

\section{RESULTS AND DISCUSSION}

\section{A. Formation of the protonated pyrimidine dimer}

The experimental methods above generate association/dissociation equilibrium reactions (1) by injecting the protonated monomer or dimer ion into gas mixtures containing the neutral monomer. Equilibrium can be achieved if the reactions in both directions are fast enough compared with the ion drift time. At $300 \mathrm{~K}$ we observed irreversible association, but at higher drift cell temperatures dissociation became fast enough to make the reaction reversible. Figure 1 displays the mass spectra obtained following the injection of the pyrimidine radical cation into the drift cell containing $\mathrm{He}$ carrier gas or a pyrimidine/He gas mixture at different temperatures. At $318 \mathrm{~K}$ in the presence of a small concentration of pyrimidine ( 0.06 Torr), the protonated pyrimidine dimer is the only ion observed indicating irreversible association. However, as the temperature of the drift cell increases, the protonated monomer is formed by the dissociation of the protonated dimer. As the temperature increases further, the intensity of the protonated dimer decreases and that of the protonated monomer increases indicating reversible association. Under these conditions the equilibrium constant $(\mathrm{K})$ for reaction (1) is obtained from Eq. (3),

$$
\mathrm{K}=\mathrm{I}\left[\mathrm{B}_{2} \mathrm{H}^{+}\right] / \mathrm{I}\left[\mathrm{BH}^{+}\right] \mathrm{P}(\mathrm{B}),
$$

where $\mathrm{B}$ is the neutral pyrimidine, $\mathrm{I}\left[\mathrm{BH}^{+}\right]$and $\left.\mathrm{I}_{2} \mathrm{~B}_{2} \mathrm{H}^{+}\right]$are the integrated signal intensities of the ATDs of the protonated monomer and protonated dimer, respectively, and $\mathrm{P}(\mathrm{B})$ is the pressure of the pyrimidine monomer in the drift cell in atm.

Equilibrium was checked by ensuring that the following two conditions are satisfied: (i) The integrated intensities of the reactant and product ions reach a constant ratio during the residence time in the cell as illustrated in Figure 2. (ii) The ATDs of the reactant and product ions overlap, indicating that the product and reactant ions are coupled reactively by the equilibrium reaction faster than their movement through the cell as shown in Figure 3(a). We also tested that the equilibrium constant $\mathrm{K}$ remained constant in the operating ranges of $\mathrm{He}$ and pyrimidine pressures. For example, for re-

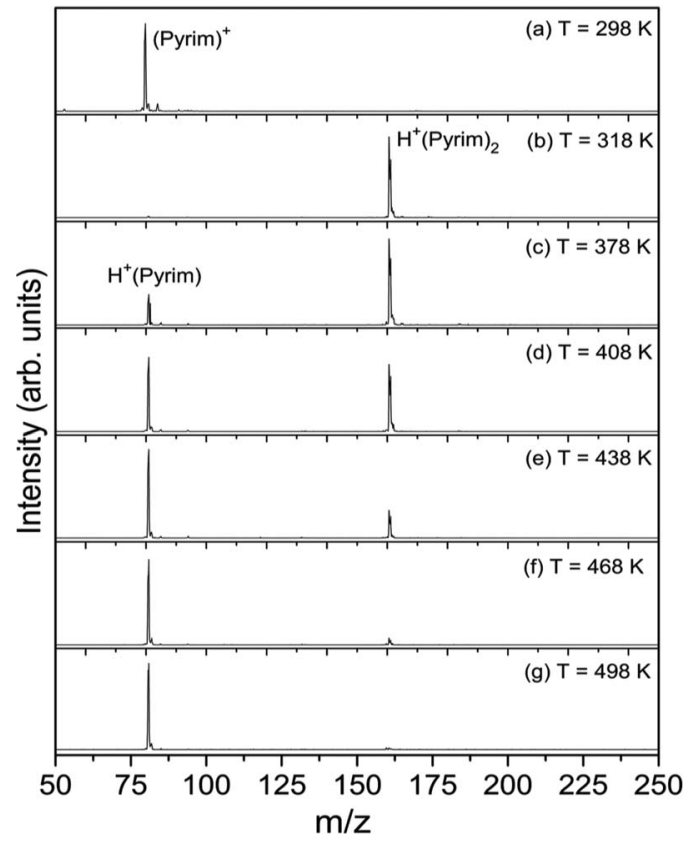

FIG. 1. Mass spectra obtained following the injection of $\mathrm{C}_{4} \mathrm{H}_{4} \mathrm{~N}_{2}{ }^{+}$. (i.e., pyrimidine ${ }^{+}$) into pyrimidine/He in the mobility cell at the temperatures as shown. Note decreasing dimer/monomer ratio $\mathrm{I}\left(\mathrm{H}^{+}\right.$ $\left(\mathrm{C}_{4} \mathrm{H}_{4} \mathrm{~N}_{2}\right)_{2} / \mathrm{I}\left(\mathrm{H}^{+} \mathrm{C}_{4} \mathrm{H}_{4} \mathrm{~N}_{2}\right)$ with increasing temperature. Total pressures, $\mathrm{P}_{\mathrm{t}}$ (Torr) inside the drift cell are: (a) $\mathrm{P}_{\mathrm{t}}=0.70$ (pure He); (b) $\mathrm{P}_{\mathrm{t}}=0.76, \mathrm{P}_{\text {pyrim }}$ $=0.06$; (c) $\mathrm{P}_{\mathrm{t}}=0.83, \mathrm{P}_{\text {pyrim }}=0.066$; (d) $\mathrm{P}_{\mathrm{t}}=0.85$, $\mathrm{P}_{\text {pyrim }}=0.068$; (e) $\mathrm{P}_{\mathrm{t}}$ $=0.88, \mathrm{P}_{\text {pyrim }}=0.071$; (f) $\mathrm{P}_{\mathrm{t}}=0.92, \mathrm{P}_{\text {pyrim }}=0.072$; and $(\mathrm{g}) \mathrm{P}_{\mathrm{t}}=0.95$, $\mathrm{P}_{\text {pyrim }}=0.073$.

action (1) to form (pyrimidine) ${ }_{2} \mathrm{H}^{+}$in neat pyrimidine vapor, without $\mathrm{He}$, in the cell at $\mathrm{P}_{\text {pyrim }}=0.39,0.59$, and 0.75 Torr we obtained $\mathrm{K}=2623,2640$, and $2603 \mathrm{~atm}^{-1}$, respectively, at a cell temperature of $523 \mathrm{~K}$, which are constant within the experimental error.

The equilibrium constant $\mathrm{K}$ was obtained at different temperatures, and $\Delta \mathrm{H}^{\circ}$ and $\Delta \mathrm{S}^{\circ}$ were obtained from the slope and intercept of the van't Hoff plot shown in Figure 3(b). All measurements were replicated at least three times. The resulting $\Delta \mathrm{H}^{\circ}$ and $\Delta \mathrm{S}^{\circ}$ values are listed in Table I.

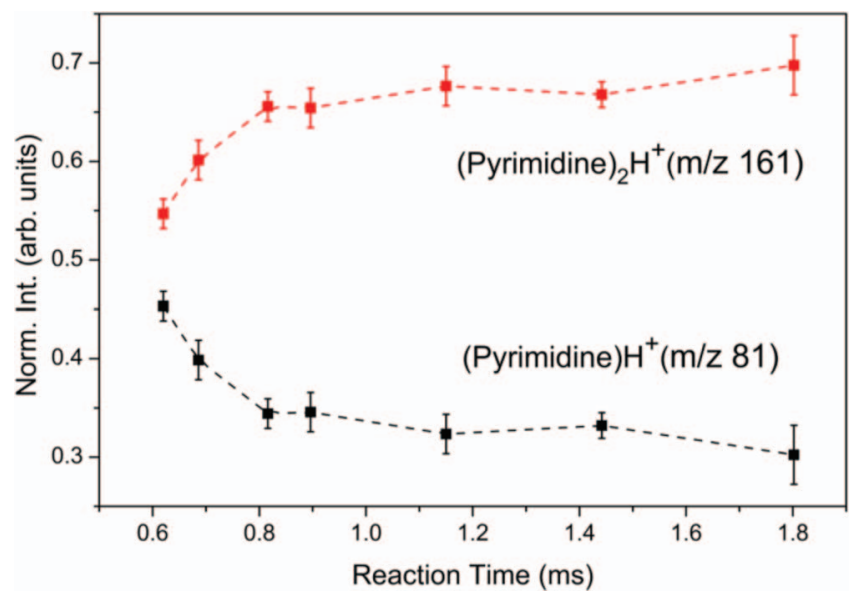

FIG. 2. Time resolved mass scan following the injection of pyrimidine $\mathrm{H}^{+}$ $(\mathrm{m} / \mathrm{z} 81)$ into the mobility cell containing 0.59 Torr pyrimidine vapor in 1.30 Torr total pressure in helium at $523 \mathrm{~K}$. Reaction time was varied by varying the cell voltage from $9 \mathrm{~V}$ to $33 \mathrm{~V}$. The time profile shows the reversible association of pyrimidine $\mathrm{H}^{+}(\mathrm{m} / \mathrm{z} 81)+$ pyrimidine $\rightarrow$ (pyrimidine ${ }_{2} \mathrm{H}^{+}$ $(\mathrm{m} / \mathrm{z} 161)$. 
(a)

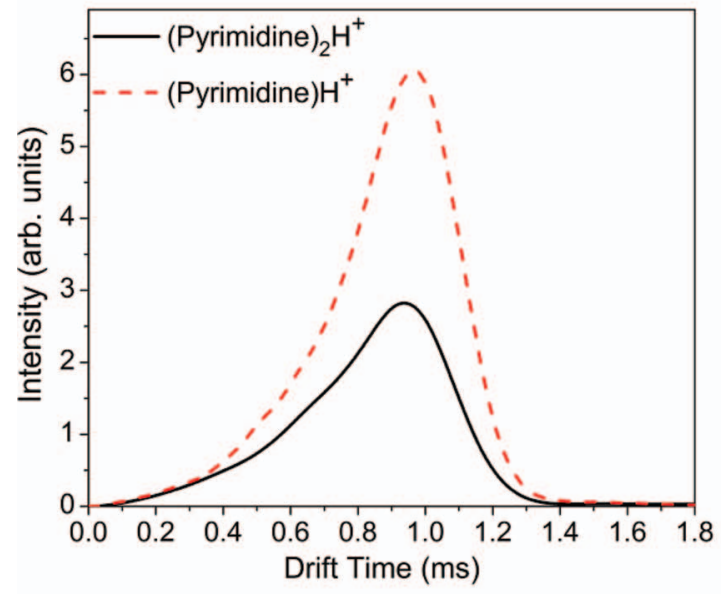

(b)

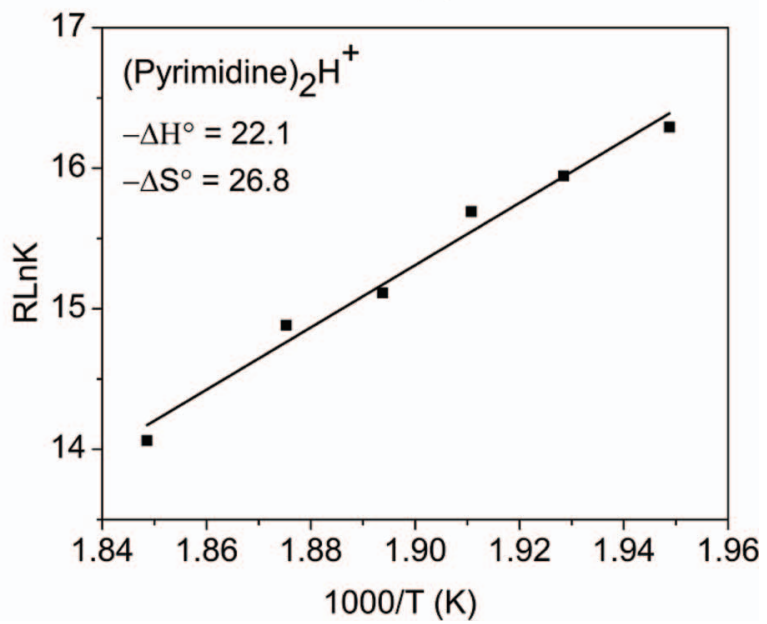

FIG. 3. (a) Arrival time distributions (ATDs) for the reversible dissociation of (pyrimidine) ${ }_{2} \mathrm{H}^{+}(\mathrm{m} / \mathrm{z} 161)$ into pyrimidine $\mathrm{H}^{+}(\mathrm{m} / \mathrm{z} 81)+$ pyrimidine in 0.59 Torr pyrimidine vapor in 1.30 Torr total pressure in helium at $523 \mathrm{~K}$. Overlapping ATDs show that the dissociation/association reaction is in equilibrium. The slow increase of the intensity of the protonated monomer and dimer at early time is due to the formation of the protonated monomer inside the drift cell at different distances as opposed to injecting the protonated monomer at zero time at the entrance of the cell. (b) van't Hoff plot for association/dissociation equilibrium forming the protonated dimer (pyrimidine) ${ }_{2} \mathrm{H}^{+}$in 0.58 Torr pyrimidine vapor in 1.3 Torr total pressure in He.

TABLE I. Thermochemistry of protonated azines and fluoropyridines and of their protonated dimers. ${ }^{\mathrm{a}}$

\begin{tabular}{|c|c|c|c|c|}
\hline Base (B) & $\Delta \mathrm{H}^{\circ}{ }_{\text {dissoc }}\left(\mathrm{B}_{2} \mathrm{H}^{+}\right)$, Expt. ${ }^{\mathrm{b}}$, Calc. $(\Delta \mathrm{E})^{\mathrm{b}}$ & $\Delta \mathrm{S}_{\text {dissoc }}^{\circ}\left(\mathrm{B}_{2} \mathrm{H}^{+}\right)$ & Proton affinity (B) $(\mathrm{NIST})^{27}$ & Proton affinity $(\mathrm{B})(\mathrm{Calc} .)^{\mathrm{b}}$ \\
\hline \multicolumn{5}{|c|}{ Azines } \\
\hline \multirow[t]{3}{*}{ Pyridine } & $25.0^{c}$ & $29.5^{\mathrm{c}}$ & 222.0 & 221.9 \\
\hline & 24.9 (T-shaped) & & & \\
\hline & 22.9 (planar) & & & \\
\hline \multirow[t]{3}{*}{ 1,2-Diazine } & 29.7 (trans-planar) & & 216.8 & 218.1 \\
\hline & 25.8 (cis-planar) & & & \\
\hline & 23.9 (T-shaped) & & & \\
\hline \multirow[t]{4}{*}{ 1,3-Diazine (pyrimidine) } & 22.1 & 26.8 & 211.7 & 211.3 \\
\hline & 22.4 (T-shaped) & & & \\
\hline & 20.9 (trans-planar) & & & \\
\hline & 19.6 (cis-planar) & & & \\
\hline \multirow[t]{2}{*}{ 1,4-Diazine } & 21.9 (T-shaped) & & 209.6 & 208.5 \\
\hline & 19.8 (planar) & & & \\
\hline \multirow[t]{2}{*}{ 1,3,5-Triazine } & 19.3 (T-shaped) & & 202.9 & 199.7 \\
\hline & 17.3 (planar) & & & \\
\hline & & Fluoropyridines & & \\
\hline \multirow[t]{2}{*}{ 2-F-pyridine } & 24.8 (planar) & & 211.4 & 210.4 \\
\hline & 23.6 (T-shaped) & & & \\
\hline \multirow[t]{3}{*}{ 3-F-pyridine } & 23.0 & 33.0 & 215.6 & 214.8 \\
\hline & 23.3 (T-shaped) & & & \\
\hline & 21.5 (planar) & & & \\
\hline \multirow[t]{2}{*}{ 4-F-pyridine } & 23.0 (T-shaped) & & 218.2 & 217.4 \\
\hline & 20.7 (planar) & & & \\
\hline \multirow[t]{2}{*}{ 2,6-Difluoro-pyridine } & 23.3 (T-shaped) & & & 199.3 \\
\hline & 19.4 (planar) & & & \\
\hline \multirow[t]{2}{*}{ Pentafluoro-pyridine } & 18.1 (T-shaped) & & 182.8 & 182.0 \\
\hline & 15.4 (planar) & & & \\
\hline
\end{tabular}

a Enthalpies and proton affinities in $\mathrm{kcal} / \mathrm{mol}$, entropies in cal $/ \mathrm{mol} \mathrm{K}$. Experimental values in bold. Estimated uncertainties: PAs, $\pm 1 \mathrm{kcal} / \mathrm{mol}, \Delta \mathrm{H}^{\circ}{ }_{\text {dissoc }}, \pm 1.2 \mathrm{kcal} / \mathrm{mol}$, and $\Delta \mathrm{S}^{\circ}{ }_{\text {dissoc, }}$ $\pm 1.8 \mathrm{cal} / \mathrm{mol} \mathrm{K}$.

${ }^{b}$ Experimental values (bold) and computational values (PAs and $\Delta \mathrm{E}$ ) from this work unless noted otherwise. Calculated PAs and $\Delta \mathrm{E}\left(\mathrm{B}_{2} \mathrm{H}^{+}\right.$) are obtained using the DFT B3LYP/6$311++\mathrm{G}^{* *}$ method.

${ }^{\mathrm{c}} \Delta \mathrm{H}^{\circ}$ dissoc (pyridine $)_{2} \mathrm{H}^{+}$and $\Delta \mathrm{S}^{\circ}$ dissoc $(\text { pyridine })_{2} \mathrm{H}^{+}$average literature values as listed in NIST WebBook. ${ }^{27}$ 


\section{(Pyrimidine) ${ }_{2} \mathrm{H}^{+}$}

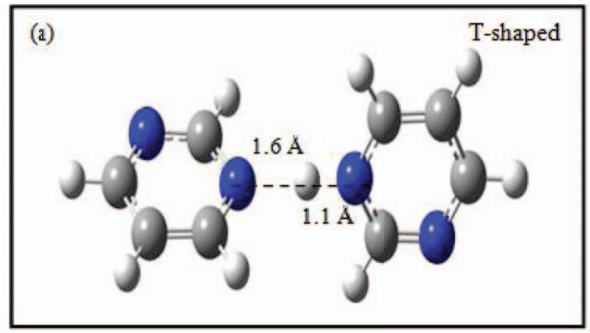

$\Delta \mathrm{E}^{\circ}=22.4(21.6)\left[\sim 90^{\circ}\right]$

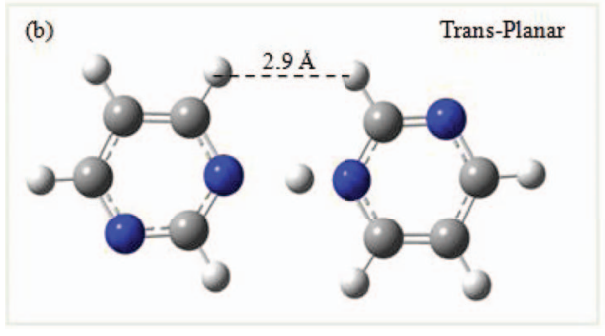

$\Delta \mathrm{E}=20.9$

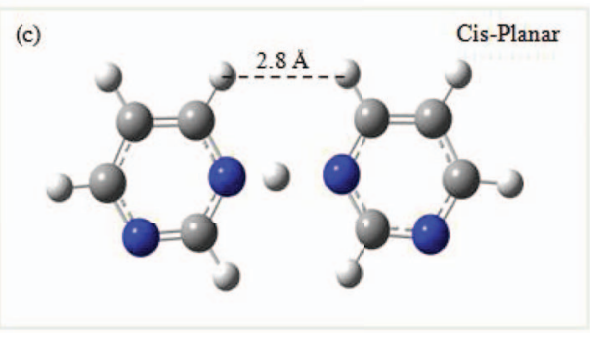

$\Delta \mathrm{E}=19.6(18.9)$

FIG. 4. DFT calculated structures of the protonated pyrimidine dimer obtained at the B3LYP/6-311++G** level. Binding energy $\Delta \mathrm{E}$ in kcal/mol, and the value in brackets is corrected for BSSE. The approximate angle between the plans of the two rings in the T-shaped structure is $90^{\circ}$.

The B3LYP/6-311++ $\mathrm{G}^{* *}$ method has been previously used to accurately compute (within $1.5 \mathrm{kcal} / \mathrm{mol}$ ) binding energies of complexes involving ionized benzene and nitrogen heterocyclic molecules similar to the present systems. ${ }^{34,36}$ This trend continues in the present study not only in the calculations of binding energies but also the proton affinities as evident from the excellent agreement between the calculated and the experimental values listed in Table I. The calculated lowest energy isomer of the proton-bound pyrimidine dimer at the B3LYP/6-311++ $\mathrm{G}^{* *}$ level has a T-shape geometry with a H-bond distance of $1.6 \AA$ as shown in Figure 4. The calculated binding energy of $22.4 \mathrm{kcal} / \mathrm{mol}$ (21.6 corrected for BSSE) is in very good agreement with the measured $-\Delta \mathrm{H}^{\circ}$ of $22.1 \pm 1.2 \mathrm{kcal} / \mathrm{mol}$. The structures and binding energies of two planar structures, obtained by rotation of the pyrimidine molecule about the hydrogen bond fixed at the equilibrium distance of $1.6 \AA$ found in the lowest energy isomer, are also shown in Figure 4. The small difference in the binding energies of the lowest energy T-shape isomer (a) and the transplanar structure (b) $(1.2 \mathrm{kcal} / \mathrm{mol})$ suggests that the two isomers may co-exist if the rotational barrier is low. However, the cis-planar structure (c) can be excluded based on the low binding energy $(19.6 \mathrm{kcal} / \mathrm{mol})$ as compared to the experimental value of $22.1 \pm 1.2 \mathrm{kcal} / \mathrm{mol}$.

\section{B. Formation of the protonated 3-F-pyridine dimer}

Figure 5 displays the mass spectra obtained at different temperatures following the injection of the methanol radical cation $\left(\mathrm{CH}_{3} \mathrm{OH}^{+\cdot}\right)$ into the drift cell containing 3-Fpyridine vapor in $\mathrm{He}$ carrier gas. The resulting protonated
3-F-pyridine undergoes reversible association with the neutral 3-F-pyridine molecule to form the protonated dimer $\mathrm{H}^{+}$(3Fpy $)_{2}$ as shown at higher temperatures where the intensity of the protonated dimer decreases and that of the protonated

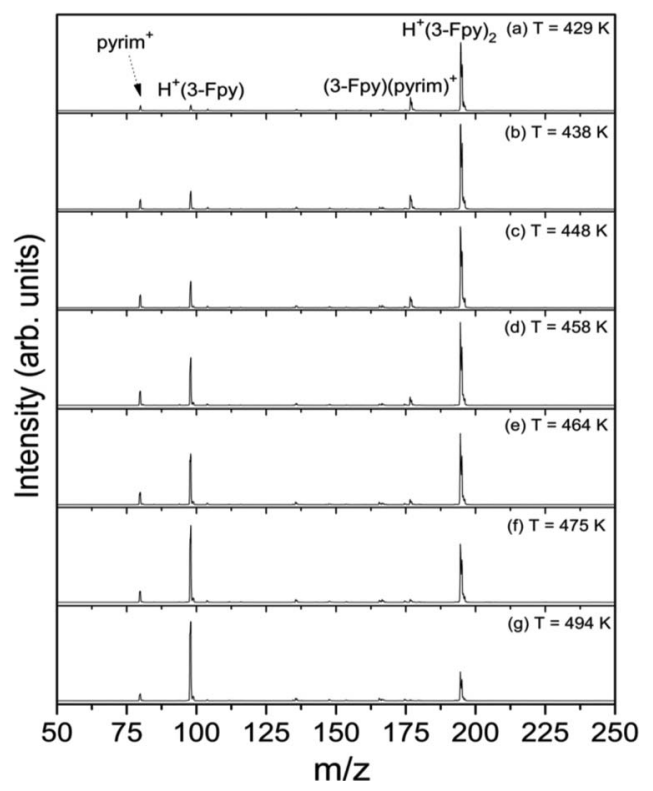

FIG. 5. Mass spectra obtained following the injection of $\mathrm{CH}_{3} \mathrm{OH}^{+\cdot} \cdot$ into 3-Fpyridine/He that forms (3-F-pyridine) $\mathrm{H}^{+}$in the mobility cell at the temperatures shown. Note decreasing dimer/monomer ratio $\mathrm{I}\left[\mathrm{H}^{+}(3-\mathrm{Fpyd})_{2}\right] /\left[\mathrm{I}\left[\mathrm{H}^{+}(3-\right.\right.$ Fpyd)] with increasing temperature. Pressures (Torr) inside the drift cell are: (a) $\mathrm{P}_{\mathrm{t}}=2.05, \mathrm{P}_{3 \text { Fpyd }}=0.24$; (b) $\mathrm{P}_{\mathrm{t}}=2.08, \mathrm{P}_{3 \text { Fpyd }}=0.25$; (c) $\mathrm{P}_{\mathrm{t}}=2.04$, $\mathrm{P}_{3 \text { Fpyd }}=0.25 ;$ (d) $\mathrm{P}_{\mathrm{t}}=2.06, \mathrm{P}_{3 \text { Fpyd }}=0.25$; (e) $\mathrm{P}_{\mathrm{t}}=2.07, \mathrm{P}_{3 \mathrm{Fpyd}}=0.25$; (f) $\mathrm{P}_{\mathrm{t}}=2.02, \mathrm{P}_{3 \text { Fpyd }}=0.25$; and $(\mathrm{g}) \mathrm{P}_{\mathrm{t}}=2.06, \mathrm{P}_{3 \text { Fpyd }}=0.26$. 


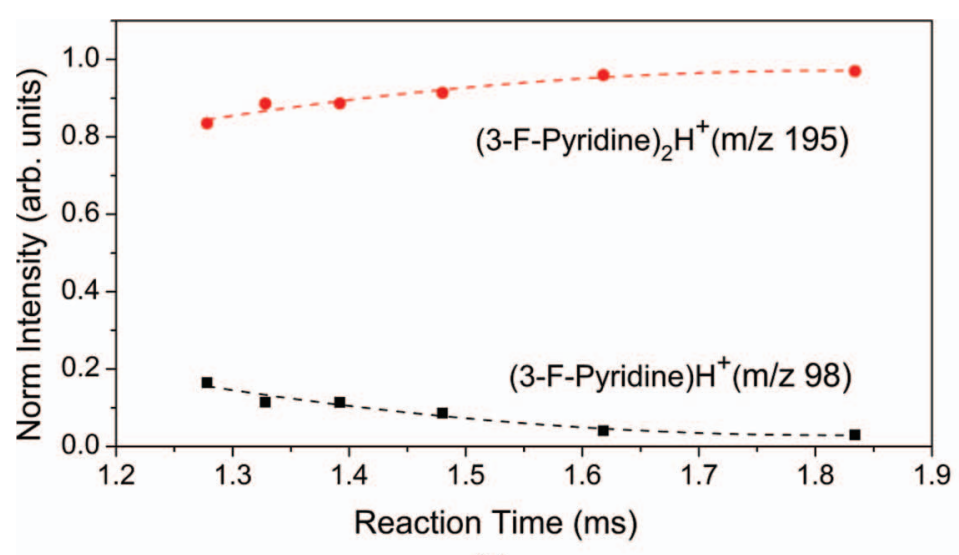

(a)

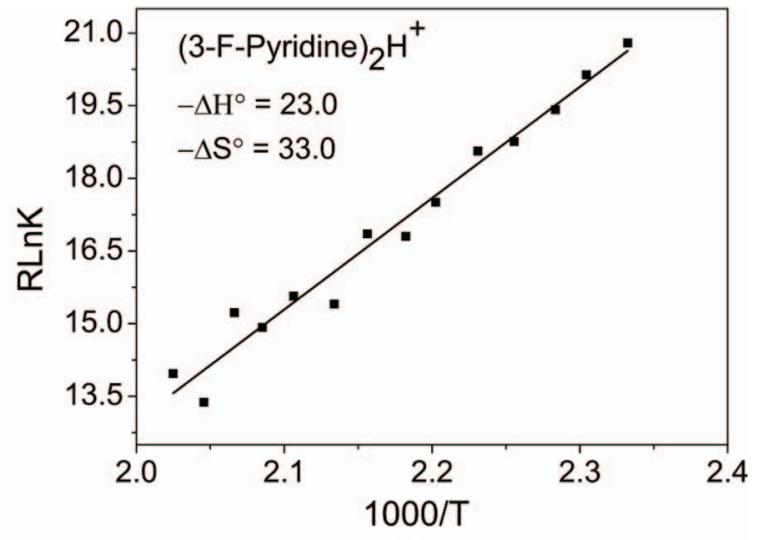

(b)

FIG. 6. (a) Time resolved mass scan of the reversible dissociation of (3-F-pyridine) ${ }_{2} \mathrm{H}^{+}\left(\mathrm{m} / \mathrm{z}\right.$ 195) into 3-F-pyridineH ${ }^{+}$(m/z 98$)+3-\mathrm{F}-$ pyridine in 0.24 Torr of 3-F-pyridine in 2.0 Torr total pressure in helium at $423 \mathrm{~K}$. Drift cell voltage was varied from $13 \mathrm{~V}$ to $33 \mathrm{~V}$. Constant ion ratio after $0.0016 \mathrm{~s}$ shows that the dissociation/association reaction reached equilibrium in the observed reaction time. (b) van't Hoff plot for association/dissociation equilibrium forming the (3-F-pyridine) ${ }_{2} \mathrm{H}^{+}$dimer in 0.24 Torr 3-F-pyridine vapor in 2.0 Torr total pressure in He.

monomer increases. Figure 6(a) displays the time-resolved intensity profiles of the protonated 3-F-pyridine monomer and dimer illustrating the approach to equilibrium under the current experiemntal conditions. The overalp of the ATDs of the reactant and product ions confirms that equilibrium has been achieved as shown in Figure S1 of the supplementary material. ${ }^{37}$ From the slope and intercept of the van't Hoff plot shown in Figure $6(\mathrm{~b}), \Delta \mathrm{H}^{\circ}$ and $\Delta \mathrm{S}^{\circ}$ values are determined as $23.0 \pm 1.2 \mathrm{kcal} / \mathrm{mol}$, and $33 \pm 2.0 \mathrm{cal} / \mathrm{mol} \mathrm{K}$, respectively.

The calculated lowest energy isomer of the proton-bound 3-F-pyridine dimer at the B3LYP/6-311++ $\mathrm{G}^{* *}$ level has a similar structure to that of the protonated pyrimidine dimer with a T-shape geometry and a H-bond distance of $1.6 \AA$ as shown in Figure 7(a). The calculated binding energy of $23.3 \mathrm{kcal} / \mathrm{mol}$ (22.6 corrected for BSSE) is in very good agreement with the measured $-\Delta \mathrm{H}^{\circ}$ of $23.0 \pm 1.2 \mathrm{kcal} / \mathrm{mol}$. The planar structure (Figure 7(b)) obtained by rotation of the 3-F-pyridine molecule about the $1.6 \AA$ hydrogen bond has a binding energy of $21.5 \mathrm{kcal} / \mathrm{mol}(20.8 \mathrm{kcal} / \mathrm{mol}$ corrected for BSSE) which is lower than the experimental value of $23.0 \mathrm{kcal} / \mathrm{mol}$.

\section{Formation of the pyrimidine ${ }^{+\cdot}$ (3-F-pyridine) radical cation dimer}

To compare the binding energies of the proton-bound and the radical cation dimers, we measured $\Delta \mathrm{H}^{\circ}$ and $\Delta \mathrm{S}^{\circ}$ for formation of the pyrimidine $\cdot+(3-F-p y r i d i n e)$ radical cation dimer under the same experimental conditions used for the protonated pyrimidine and 3-F-pyridine dimers. The primidine radical cation is generated by charge transfer from the injected $\mathrm{CH}_{3} \mathrm{OH}^{+}+$to trace pyrimidne vapor present in the drift cell. The resulting pyrimidne radical cation undergoes association with the 3-F-pyridine molecule to form the pyrimidine ${ }^{+}(3$-Fyp) radical cation dimer as shown in Figure 5. From the slope and intercept of the van't Hoff plot shown in Figure $8(\mathrm{a}),-\Delta \mathrm{H}^{\circ}$ and $-\Delta \mathrm{S}^{\circ}$ values of 19.2 $\pm 1 \mathrm{kcal} / \mathrm{mol}$ and $27.1 \pm 2 \mathrm{cal} / \mathrm{mol}$. K, respectively, are determined for the formation of the pyrimidine ${ }^{+}$(3-Fyp) radical cation dimer. It is clear that measured binding energy for the radical cation dimer is signifcantly lower than that of the protonated pyrimidine $(22.7 \mathrm{kcal} / \mathrm{mol})$ or $3-\mathrm{F}-$ pyridine $(23.0 \mathrm{kcal} / \mathrm{mol})$ dimers. The difference is mainly due to the stronger ion-dipole interaction in the ionic $\mathrm{H}$-bond of the protonated dimer where the proton bridges between two

\section{(3-F-Pyridine) ${ }_{2} \mathrm{H}^{+}$}

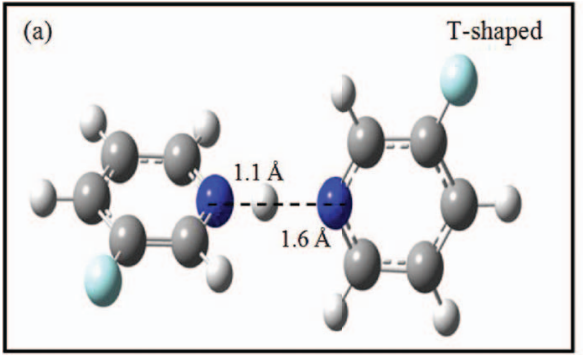

$\Delta \mathrm{E}=23.3(22.6),\left[\sim 90^{\circ}\right]$

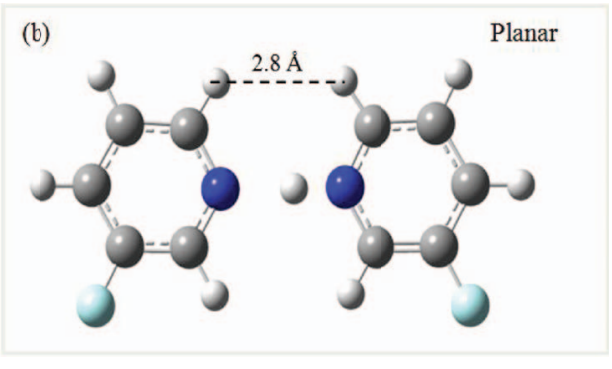

$\Delta \mathrm{E}=21.5(20.8)$

FIG. 7. DFT calculated structures of the protonated 3-F-pyridine dimer obtained at the B3LYP/6-311++G** level. Binding energy $\Delta \mathrm{E}$ in $\mathrm{kcal} / \mathrm{mol}$, and the values in brackets are corrected for BSSE. The approximate angle between the plans of the two rings in the T-shaped structure is $90^{\circ}$. 


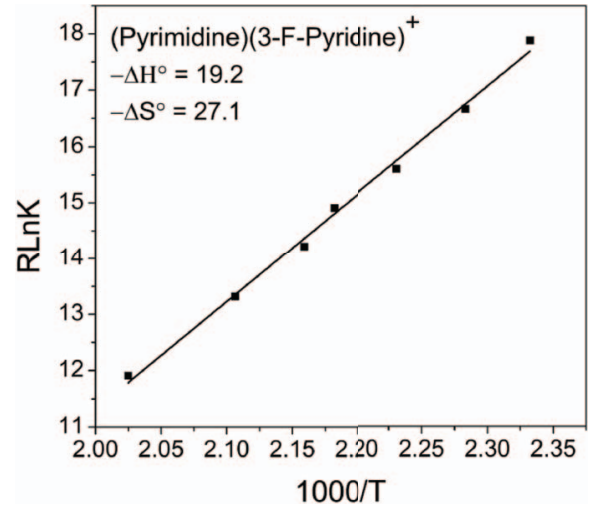

(a)

Pyrimidine ${ }^{+}(3-F-P y r i d i n e)$

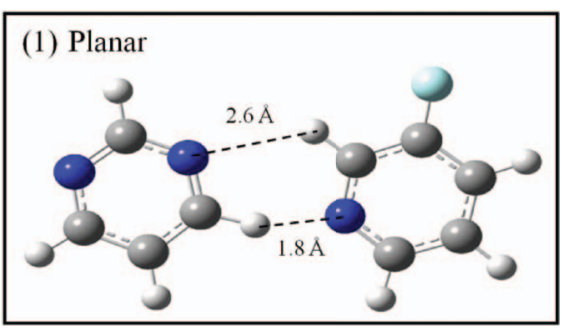

$\Delta \mathrm{E}=18.5$

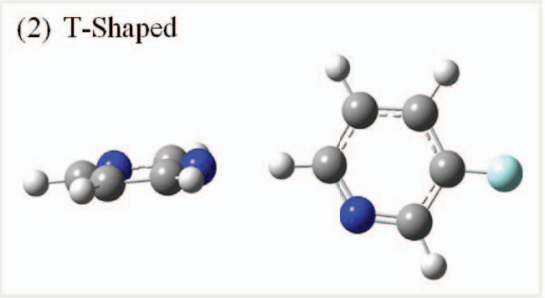

$\Delta \mathrm{E}=15.5\left(\sim 85^{\circ}\right)$

(4) T-Shaped

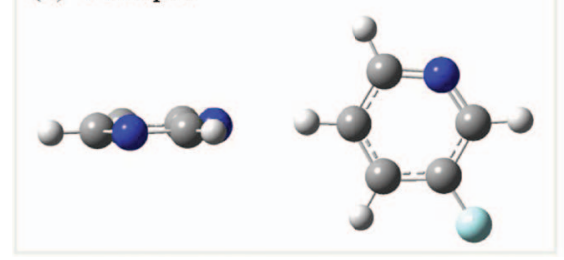

$\Delta \mathrm{E}=13.2\left(\sim 90^{\circ}\right)$
(3) Propeller

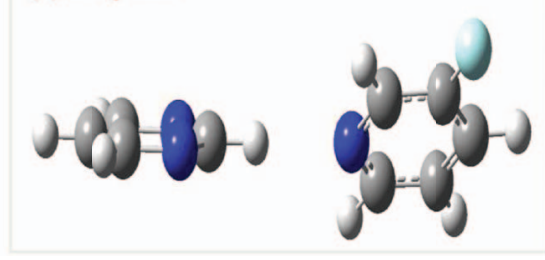

$\Delta \mathrm{E}=14.9\left(\sim 30^{\circ}\right)$

(5) Propeller
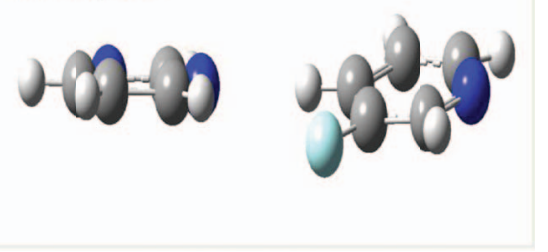

$\Delta \mathrm{E}=12.4\left(\sim 5-10^{\circ}\right)$

(b)

FIG. 8. (a) van't Hoff plot for association/dissociation equilibrium forming the pyrimidine ${ }^{+}+(3$-F-pyridine) radical cation dimer in 0.24 Torr 3-F-pyridine vapor

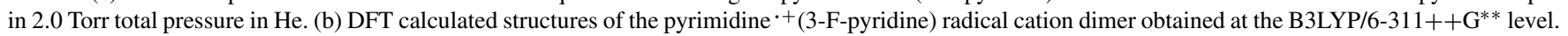
The approximate angles between the plans of the two rings are given in brackets.

nitrogen atoms, and the weaker interaction in the less ionic $\mathrm{C}-\mathrm{H}^{\delta+} \ldots \mathrm{N}$ bond in the radical cation dimer. As shown in Figure $8(\mathrm{~b})$, the lowest energy isomer of the pyrimidine ${ }^{+}(3-$ Fyp) radical cation dimer has a planar structure with a $\mathrm{C}-$ $\mathrm{H}^{\delta+} \ldots \mathrm{N}$ bond length of $1.8 \AA$ between a hydrogen atom of the pyrimidine cation ring and the nitrogen atom of the 3-F-pyridine molecule. The calculated binding energy of $18.5 \mathrm{kcal} / \mathrm{mol}$ is in very good agreement with the experimental value of $19.2 \pm 1 \mathrm{kcal} / \mathrm{mol}$. Other higher energy isomers show $\mathrm{H}$-bonding interaction between the $\mathrm{C}-$ $\mathrm{H}$ of the 3-F-pyridine molecule and the nitrogen atom of the pyrimidine cation (isomers 2 and 4, Figure 8(b)). Isomers with perpendicular structures between the two rings (isomers 2 and 4, Figure 8(b)) have lower binding 
energies $(15-13 \mathrm{kcal} / \mathrm{mol})$ than the lowest energy isomer 1 (18.5 kcal/mol).

\section{Calculations of the binding energies and structures of selected proton-bound dimers}

The binding energies of further protonated dimers of diazine, triazine, and fluorinated pyridine dimers, and the proton affinities of all the monomers were obtained computationally. Table I shows the results for the lowest energy isomers, and for some isomeric structures with different inter-plane angles between the two rings, corresponding to rotation about the hydrogen bond, which are of interest concerning rotational barriers. The energies of these structures were calculated by restricting the $\mathrm{H}$-bond distance to that found in the lowest energy isomer and allowing rotation of the rings about the hydrogen bond axis. Figures 9 and 10 show the geometries including some bond lengths in the calculated structures. The computed total energies of all the monomers and dimers, including zero point energies, are given in the supplementary material. $^{37}$

The results in Table I show very good agreement between experiment and theory both for the proton affinities and the dimer bonding energies. The experimental and calculated values agree mostly within $\pm 1.5 \mathrm{kcal} / \mathrm{mol}$, which is comparable to the experimental uncertainty. This suggests that the calculated values for the other species, for which there are no experimental data, may be similarly accurate.

\section{E. Relations between proton affinities and dimer bonding energies, and the effects of internal dipoles}

As noted above, the hydrogen bonding energies of $\mathrm{NH}^{+} \mathrm{N}$ homodimers of diverse alkylamines and alkylpyridines remain nearly constant at $24 \pm 1 \mathrm{kcal} / \mathrm{mol}$, and similarly, nearly constant at $30 \pm 2 \mathrm{kcal} / \mathrm{mol}$ for diverse $\mathrm{OH}^{+} \mathrm{O}$ type homodimers, for bases whose proton affinities vary over 30 $\mathrm{kcal} / \mathrm{mol} .^{1,11,12}$ In these systems, increasing alkyl substitution increases the polarizabilities and proton affinities, which makes the $\mathrm{N}$ lone pairs of the neutral bases stronger hydrogen acceptors but also makes the $-\mathrm{NH}^{+}$groups of the ions weaker proton donors, keeping the bond energies nearly constant.

The present work examines dimers of bases whose proton affinities vary due to a different reason, electron withdrawing $\mathrm{N}$ atoms in the ring, or $\mathrm{F}$ substituents on the ring. These dimers show different effects from the previously observed constant binding energies of $\mathrm{NH}^{+} \mathrm{N}$ homodimers. In contrast, in the present compounds, the homodimer binding energies vary significantly (Table I and Figures 9 and 10). From (pyridine) ${ }_{2} \mathrm{H}^{+}$to (pentafluoropyridine) ${ }_{2} \mathrm{H}^{+}$, the PAs of the bases decrease by $39.2 \mathrm{kcal} / \mathrm{mol}$ and the dimer binding energies decrease by $8.9 \mathrm{kcal} / \mathrm{mol}$. Figure 11 shows the correlation between the calculated proton affinities of the monomer molecules and the binding energies of the protonbound dimers. With the exception of the 1,2-diazine, two groups of bases show strong correlations between the binding energies of the proton-bound dimers and the EA of the base monomer. The first group (bottom line) includes pyridine, 4-F-pyridine, 3-F-pyridine, 1,3-diazine (pyrimidine),
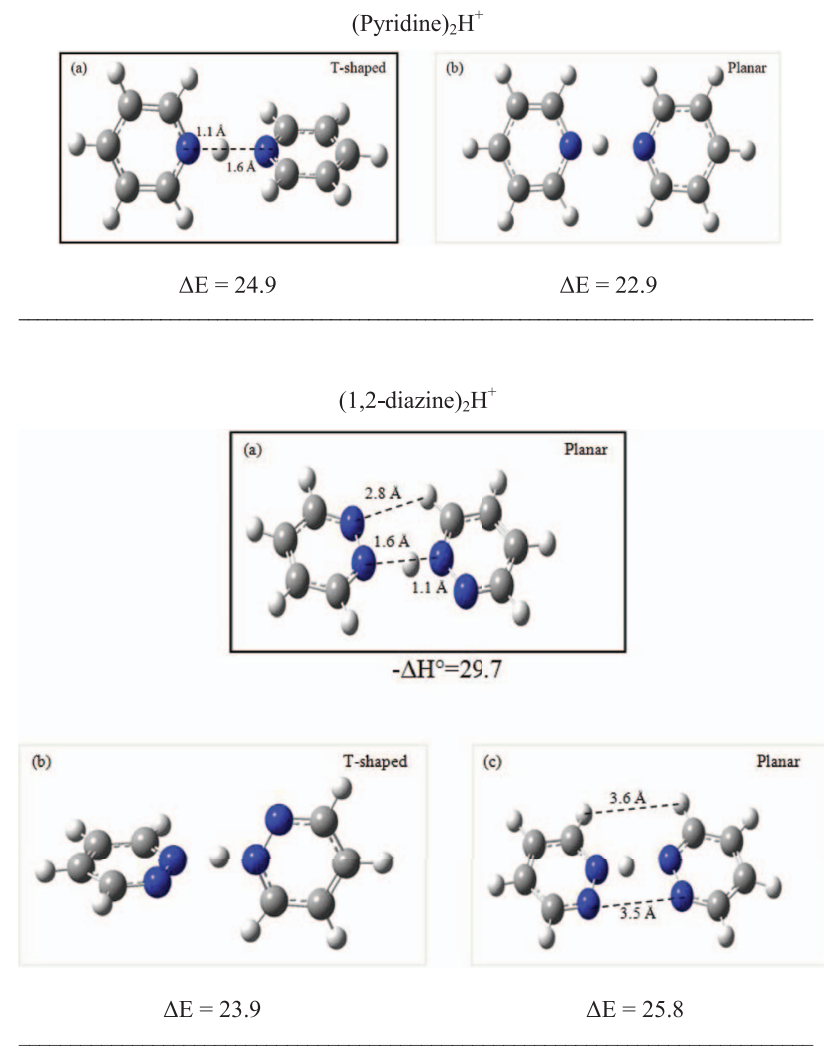

(a)

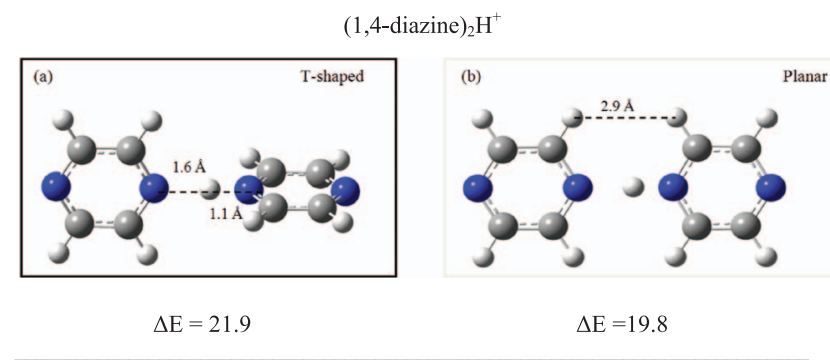

$(1,3,5 \text {-triazine })_{2} \mathrm{H}$

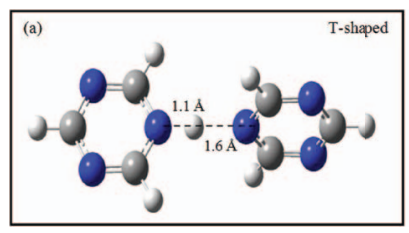

$\Delta \mathrm{E}=19.3$

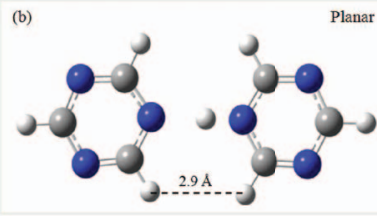

$\Delta \mathrm{E}=17.3$ (b)

FIG. 9. DFT calculated structures of the proton-bound dimers of pyridine, 1,2-diazine, 1,4-diazine, and 1,3,5-triazine obtained at the B3LYP/6$311++\mathrm{G}^{* *}$ level. The approximate angle between the plans of the two rings in the T-shaped structures is $90^{\circ}$.

1,4-diazine, and 1,3,5-triazine where the PAs decrease as 222.0, 218.2, 215.6, 211.7, 209.6, and $202.8 \mathrm{kcal} / \mathrm{mol}$, and the calculated binding energies $(\Delta \mathrm{E})$ of the T-shaped homodimers decrease in the same order, as 24.9. 23.0, 23.3, 22.4, 21.9 , and $19.3 \mathrm{kcal} / \mathrm{mol}$, respectively. The second group (top line) includes the ortho substituted compounds 2-F-Pyridine, 


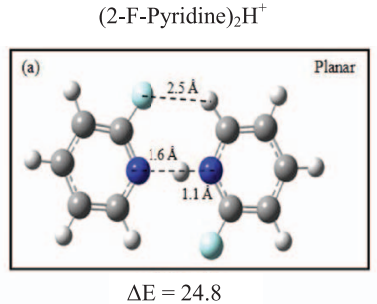

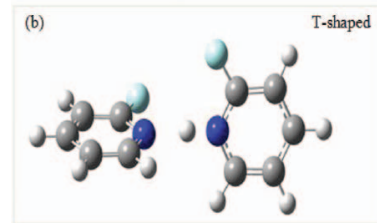

$\Delta \mathrm{E}=23.6$ (4-F-Pyridine $)_{2} \mathrm{H}^{+}$

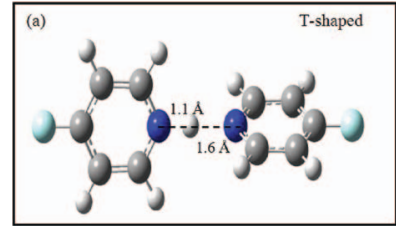

$\Delta \mathrm{E}=23.0$

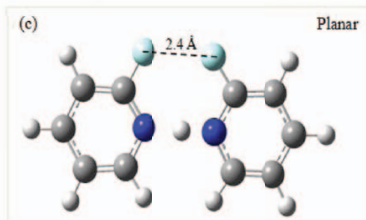

$\Delta \mathrm{E}=11.9$

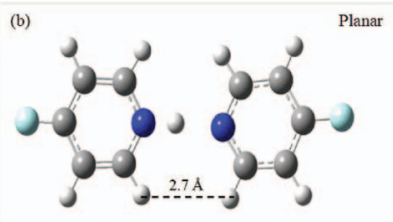

$\Delta \mathrm{E}=20.7$

(a)

(2,6-di-F-Pyridine $)_{2} \mathrm{H}^{+}$

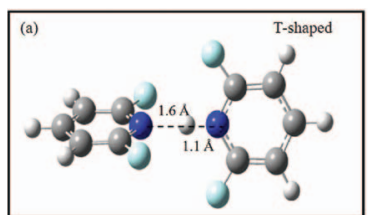

$\Delta \mathrm{E}=23.3$

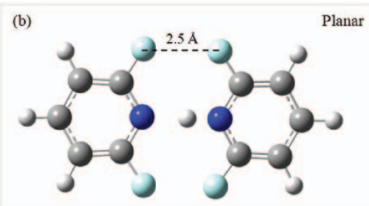

$\Delta \mathrm{E}=19.4$
(Pentafluoropyridine $)_{2} \mathrm{H}^{+}$

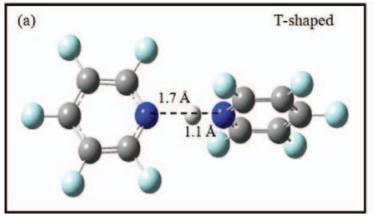

$\Delta \mathrm{E}=18.1$

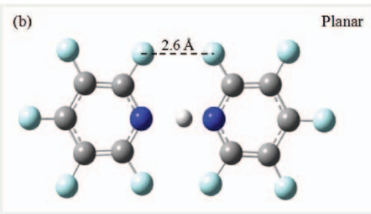

$\Delta \mathrm{E}=15.4$ (b)

FIG. 10. DFT calculated structures of the proton-bound dimers of selected fluoropyridine molecules obtained at the B3LYP/6-311++ $\mathrm{G}^{* *}$ level. Binding energy $\Delta \mathrm{E}$ in $\mathrm{kcal} / \mathrm{mol}$. The approximate angle between the plans of the two rings in the T-shaped structures is $90^{\circ}$.

2,6-di-F-pyridine and pentafluoropyridine. This group will be discussed under the effects of ortho substitutions below.

Figure 11, bottom line, shows that the binding energies of the lowest energy T-shaped rotamers of dimers with meta and para substitution, decrease linearly with decreasing PAs of the monomers. Interestingly, 3-F-pyridine and 4-F-pyridine, where the T-shaped rotamers also have the strongest binding

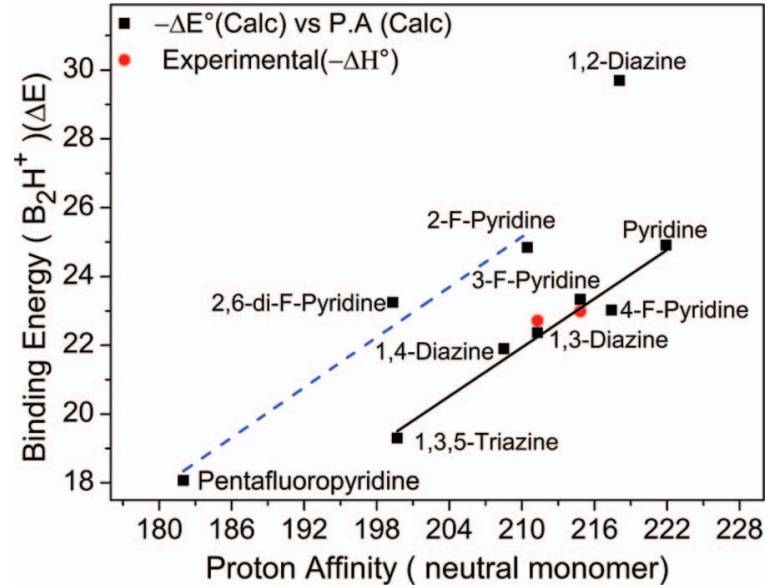

FIG. 11. Calculated binding energies of the proton-bound dimers and the proton affinities of the monomer molecules. Measured binding energies (this work) are shown in red circles. The top line (dashed blue) includes the ortho substituted compounds 2-F-pyridine, 2,6-di-F-pyridine, and pentafluoropyridine.

energies, fall on the same line. The parallel variation of PAs and dimer binding energies may be due to the same physical factors, i.e., electronegative substitution that introduces negatively charged atoms in or on the rings. These negative charge centers and the neighboring positive carbon atoms form internal dipoles. For example, the NBO atomic charges for neutral 1,3-diazine (Figure S2 of the supplementary material) ${ }^{37}$ show that the $\mathrm{C}-\mathrm{N}-\mathrm{C}$ group (atomic charges $0.281,-0.473,0.085$, respectively) about each nitrogen forms a dipole with the positive end oriented in an angle toward the other negative nitrogen atom. This results in a stabilizing charge-dipole interaction with the neutral molecule, but this stabilizing effect decreases in the protonated molecule. In these ions the charges on the unprotonated $\mathrm{C}-\mathrm{N}-\mathrm{C}$ group remain similar (atomic charges $0.352,-0.405,0.175$ ) but its dipole now interacts not with a negative second nitrogen but with a nearly neutral protonated $\mathrm{N}-\mathrm{H}^{+}$group (atomic charges $-0.465,0.448$ ). The loss of the stabilizing charge-dipole interaction by protonation increases the energy of the ion and decreases the proton affinity, compared with pyridine that lacks this effect. Similar effects may cause the variation of proton affinities in the order 1,2-diazine $>$ 1,3-diazine $>1$,4-diazine, as the internal dipoles align increasingly optimally for stabilizing interactions with the second nitrogen atom in the neutral bases.

The internal dipoles that decrease the PAs by this effect can also have a destabilizing effect in the dimer ions, not directly by affecting the hydrogen bond, but by dipoledipole interactions between the component rings. ${ }^{38}$ For example, in the T-shaped isomer of $(1,3 \text {-diazine })_{2} \mathrm{H}^{+}$the two component rings both contain a $\mathrm{C}-\mathrm{N}-\mathrm{C}$ group dipole of the nonhydrogen-bonding nitrogen (atomic charges $0.309,-0.473$, 0.127 in the neutral component and $0.340,-0.418,0.154$ in the protonated component) (see Figure S3 of the supplementary material). ${ }^{37}$ The dipoles point away from each other in the T-shaped and planar trans-rotamers, but their axes intersect in the planar cis-rotamer, making this the highest energy (lowest $\Delta \mathrm{H}^{\circ}{ }_{\text {dissoc }}$ ) rotamer. Correspondingly, the binding energies of these rotamers change as planar-cis $<$ planar-trans 
$<$ T-shaped, increasing with decreasing repulsion of the internal dipoles.

Comparing the T-shaped isomers of the various diazine dimers in Figures 4 and 9, the binding energies are in the order 1,2-diazine $>1,3$-diazine $>1$,4-diazine, which is similar to the order that the internal dipoles are aligned closer to the strongest repulsive $180^{\circ}$ angle. Here also 1,3,5-triazine with multiple dipole interactions shows the greatest effect, i.e., the weakest binding energy among the azine dimers.

\section{Rotation about the hydrogen bond, and relative energies of the rotamers}

In all the azines in Table I and Figures 4 and 9, except 1,2diazine, the T-shaped isomers have the lowest energy. This isomer avoids repulsive interactions between the ortho hydrogens of the components, which occurs in the planar cis and trans conformations. The various conformations also have various charge-dipole and dipole-dipole interactions as discussed above. Because of these effects, all the dimers have different energies in the planar cis and trans, and the T-shaped rotamer, differing by $2-4 \mathrm{kcal} / \mathrm{mol}$ as Table I and Figures 4 and 9 show. Full rotation about the hydrogen bond requires passing through all of these conformations and their respective energies, which creates a barrier of this magnitude to the rotation.

\section{Effects of ortho substitution}

The top correlation line in Figure 11 that contains ortho substituted compounds is displaced upward from the bottom line by bonding energies larger by about $4 \mathrm{kcal} / \mathrm{mol}$. This may be due to attractive interaction between the partial positive charge on the ortho hydrogen of one ring and the negative charge on the $\mathrm{F}$ substituent of the other ring as shown in the "trans" structure of the (2-F-pyridine) ${ }_{2} \mathrm{H}^{+}$dimer displayed in Figure 10 where the $\mathrm{H}$. . F distance is $2.5 \AA$. Similarly, in the proton-bound dimer of 1,2-diazine, the distance between the ortho $\mathrm{H}$ atom of one ring and the ortho $\mathrm{N}$ atom of the other ring (2.8 $\AA$, Fig. 10) is slightly larger than the distance between the other two $\mathrm{N}$ atoms $(2.7 \AA)$ involved in the proton sharing $\left(\mathrm{N} \cdots \mathrm{H}^{+}-\mathrm{N}\right)$. This stabilizing ortho interaction can be seen also as stretched $\mathrm{C}-\mathrm{H}^{\delta+}-\mathrm{N}$ bonds forming multiple hydrogen bonded structures. The anomalously large binding energy of $29.7 \mathrm{kcal} / \mathrm{mol}$ for the $(1,2 \text {-diazine })_{2} \mathrm{H}^{+}$ is similar to that of (adenine $)_{2} \mathrm{H}^{+}\left(\Delta \mathrm{H}^{\circ}{ }_{\mathrm{D}}=30.3 \mathrm{kcal} / \mathrm{mol}\right)$ and (thymine) ${ }_{2} \mathrm{H}^{+}\left(\Delta \mathrm{H}^{\circ}{ }_{\mathrm{D}}=30.1 \mathrm{kcal} / \mathrm{mol}\right)$, which were attributed to a second hydrogen bond in these complexes, while in (cytosine) ${ }_{2} \mathrm{H}^{+}$three hydrogen bonds could be formed resulting in an even larger $\Delta \mathrm{H}^{\circ}{ }_{\mathrm{D}}=38.3 \mathrm{kcal} / \mathrm{mol}^{9}{ }^{9,26}$

On the other hand, the most weakly bonded protonated dimer of pentafluoropyridine $(15.4 \mathrm{kcal} / \mathrm{mol}$ in the planar structure, Fig. 10) allows F-F repulsive interaction in the ortho positions of the two rings as shown from short F...F distance of $2.6 \AA$. This increases the energy and decreases $\Delta \mathrm{H}^{\circ}{ }_{\text {dissoc }}$ for this conformation.

As has been established in previous studies of protonbound dimers and discussed above, the change in the basic- ity has compensating effects on the hydrogen donor and acceptor properties. ${ }^{7,9,11-13}$ This is evidently not enough in the present bases, where the bond weakening effect of decreasing basicity of the hydrogen acceptor is not fully compensated for by the increased hydrogen donor ability of the ion in forming the hydrogen bond. These observed relations between the proton affinities of the monomers, the binding energies of the dimer ions, and the orientations of the internal dipoles, support the general conclusion that electrostatic charge-dipole and dipole-dipole interactions can determine the relative dimer binding energies for the various diazines and triazines. However, there are other complex interactions in these protonated and neutral components that require further theoretical analysis.

\section{SUMMARY AND CONCLUSIONS}

The binding energies of homodimers of protonated diazines, triazines, and fluropyridines were measured and calculated. The binding energies show an unusual trend for ionic hydrogen bonded homodimers, in varying significantly with structure and with the proton affinities of the monomers, while other homodimer ions without the electron-withdrawing substituents have constant binding energies over a wide range of monomer structures and proton affinities.

These trends can be explained partly by the negatively charged substituent in-ring $\mathrm{N}$ or on-ring $\mathrm{F}$ atoms, which create internal dipoles. These dipoles can interact attractively with the other negative $\mathrm{N}$ atoms in the neutrals, but this stabilizing interaction is decreased or lost in the protonated ions, resulting in decreased proton affinities. These dipoles can also interact repulsively between the components of the dimers, depending on the relative orientations of the two rings. If these PA and binding energy effects are both due to internal dipoles in the monomers, this may account for the correlation of decreasing PAs and decreasing binding energies. In addition, attractive or repulsive interactions involving atoms in ortho positions to the hydrogen bond can cause the strongest or weakest dimer binding, respectively, in the present dimers. These complex effects require detailed theoretical analysis.

\section{ACKNOWLEDGMENTS}

We thank the National Science Foundation (CHE0911146) and NASA (NNX08AI46G) for the support of this work. The authors are grateful to King Abdulaziz University for the partial support of this work.

\footnotetext{
${ }^{1}$ E. Herbst and E. F. van Dishoeck, Annul. Rev. Astron. Astrophys. 47, 427480 (2009)

${ }^{2}$ N. Balucani, Chem. Soc. Rev. 41, 5473-5483 (2012).

${ }^{3}$ A. S. Burton, J. C. Stern, J. E. Elsia, D. P. Glavin, and J. P. Dworkin, Chem. Soc. Rev. 41, 5459-5472 (2012).

${ }^{4}$ G. A. Jeffrey, An Introduction to Hydrogen Bonding (Oxford University Press, Oxford, UK, 1997.

${ }^{5}$ B. E. Conway, Ionic Hydration in Chemistry and Biophysics (Elsevier, Amsterdam, 1981).

${ }^{6}$ M. Meot-Ner (Mautner), Chem. Rev. 105, 213 (2005); 112, PR22-PR103 (2012).

${ }^{7}$ W. R. Davidson, J. Sunner, and P. Kebarle, J. Am. Chem. Soc. 101, 1675 (1979).
} 
${ }^{8}$ J. E. Del Bene, J. Am. Chem. Soc. 99, 3617 (1977).

${ }^{9}$ M. Meot-Ner (Mautner), J. Am. Chem. Soc. 101, 2396 (1979).

${ }^{10}$ S. A. McLuckey, D. Cameron, and R. G. Cooks, J. Am. Chem. Soc. 103, 1313-1317 (1981)

${ }^{11}$ J. W. Larson and T. B. McMahon, J. Am. Chem. Soc. 104, 6255 (1982).

${ }^{12}$ M. Meot-Ner (Mautner) and L. W. Sieck, J. Am. Chem. Soc. 105, 2956 (1983).

${ }^{13}$ M. Meot-Ner, J. Am. Chem. Soc. 106, 1257 (1984).

${ }^{14}$ K. Hiraoka, H. Takimoto, and S. Yamabe, J. Phys. Chem. 90, 5910 (1986); K. Hiraoka, H. Takimoto, and K. Morise, J. Am. Chem. Soc. 108, 5683 (1986).

${ }^{15}$ X. Cheng, Z. Wu, and C. Fenselau, J. Am. Chem. Soc. 115, 4844-4848 (1993).

${ }^{16}$ R. A. Jockusch and E. R. Williams, J. Phys. Chem. A 102, 4543-4550 (1998).

${ }^{17}$ P. M. Mayer, J. Chem. Phys. 110, 7779 (1999).

${ }^{18}$ E. J. Bieske and O. Dopfer, Chem. Rev. 100, 3963 (2000).

${ }^{19}$ T. D. Fridgen, J. D. Keller, and T. B. McMahon, J. Phys. Chem. A 105, 3816 (2001).

${ }^{20}$ T. D. Fridgen and T. B. McMahon, J. Phys. Chem. A 106, 1576 (2002).

${ }^{21}$ T. D. Fridgen, J. Phys. Chem. A 110, 6122 (2006).

${ }^{22}$ M. B. Burt and T. D. Fridgen, J. Phys. Chem. A 111, 10738-10744 (2007).

${ }^{23}$ G. H. Gardenier, J. R. Roscioli, and M. A. Johnson, J. Phys. Chem. A 112, 12022-12026 (2008)

${ }^{24}$ H. K. Gerardi, G. H. Gardenier, U. Viswanathan, S. M. Auerbach, and M. A. Johnson, Chem. Phys. Lett. 501, 172-178 (2011).

${ }^{25}$ R. Wu, R. A. Marta, J. K. Martens, K. R. Eldridge, and T. B. McMahon, J. Am. Soc. Mass Spectrom. 22, 1651-1659 (2011).

${ }^{26}$ B. Yang, R. R. Wu, G. Berden, J. Oomens, and M. T. Rodgers, J. Phys. Chem. B 117, 14191-14201 (2013); B. Yang, R. R. Wu, and M. T. Rodgers, Anal. Chem. 85, 11000-11006 (2013).
${ }^{27}$ M. Meot-Ner (Mautner) and S. G. Lias "Binding energies between ions and molecules, and the thermochemistry of cluster ions," in NIST Chemistry WebBook, NIST Standard Reference Database Vol. 69, edited by P. J. Linstrom and W. G. Mallard (National Institute of Standards and Technology, Gaithersburg, MD, 2013), see http://webbook.nist.gov (retrieved November 20, 2013).

${ }^{28}$ K. Norrman and T. B. McMahon, Int. J. Mass Spectrom. 183, 381 (1999).

${ }^{29}$ O. Mo, M. Yanez, and J. Elguero, J. Org. Chem. 52, 1713 (1987).

${ }^{30}$ M. Rusyniak, Y. Ibrahim, E. Alsharaeh, M. Meot-Ner, and M. S. El-Shall, J. Phys. Chem. A 107, 7656-7666 (2003).

${ }^{31}$ Y. Ibrahim, E. Alsharaeh, M. Meot-Ner, M. S. El-Shall, and S. Scheiner, J. Am. Chem. Soc. 127, 7053-7064 (2005).

${ }^{32}$ P. O. Momoh, A. M. Hamid, S. A. Abrash, and M. S. El-Shall, J. Chem. Phys. 134, 204315 (2011).

${ }^{33}$ A. Soliman, A. M. Hamid, I. K. Attah, P. O. Momoh, and M. S. El-Shall, J. Am. Chem. Soc. 135, 155-166 (2013).

${ }^{34}$ A. M. Hamid, P. Sharma, R. Hilal, S. Elroby, S. G. Aziz, A. O. Alyoubi, and M. S. El-Shall, J. Chem. Phys. 139, 084304 (2013).

${ }^{35}$ M. J. Frisch, G. W. Trucks, H. B. Schlegel et al., Gaussian 03, Revision C.02, Gaussian, Inc., Pittsburgh, PA, 2004.

${ }^{36}$ I. K. Attah, A. M. Hamid, M. Meot-Ner (Mautner), M. S. El-Shall, S. G. Aziz, and A. O. Alyoubi, J. Phys. Chem. A 117, 10588-10597 (2013).

${ }^{37}$ See supplementary material at http://dx.doi.org/10.1063/1.4867288 for the arrival time distributions (ATDs) for the reactant and product ions to verify the attainment of equilibrium (Figure S1), calculated total energies of diazines, protonated diazines, and protonated dimer ions obtained at the B3LYP/6-311++ $\mathrm{G}^{* *}$ (Table S1), calculated atomic charges and geometries of neutral and protonated monomers and homodimers (Figure S2).

${ }^{38}$ C. V. Rama Rao, C. Jacob, and A. K. Chandra, J. Chem. Soc. Faraday Trans. 78, 3025 (1982). 